\title{
Prediction of Stability of Thin Wall Ribs in High Speed Machining
}

\author{
Vignesh Suresh ${ }^{1}$, Gopinath $\mathbf{M}^{2}$, Prabhu Raja $\mathbf{V}^{3}$, Palpandian $\mathbf{P}^{4}$ \\ ${ }^{1,2}$ Bachelor of Engineering in Mechanical Engineering, PSG College of Technology, Coimbatore, India \\ ${ }^{3}$ Associate Professor, Dept. of Mechanical Engineering, PSG College of Technology, Coimbatore, India \\ ${ }^{4}$ Associate Professor, Dept. of Mechanical Engineering, Christ University, Bangalore, India
}

\begin{abstract}
The existence of chatter in thin rib structure is mainly due to the reduction in stiffness of the structure. Hence, it is very significant to simulate the dynamic behavior of a thin wall structure in determining dynamic stiffness and natural frequency. Finite element analysis is carried out for a thin wall structure of different thickness to investigate the stiffness and natural frequency change. Stability lobe diagram is plotted for each rib thickness and the minimum axial depth of cut is found out for each case which represents the unconditional stable zone while machining.
\end{abstract}

Keywords: FEA, frequency response function, stability lobes, minimum depth of cut

\section{Introduction}

High-speed milling is growing very rapidly in aerospace, automotive, die making and many other industries due to its advantages such as higher material removal rates (MRR), better surface finish and lower cost and so on. However, the unstable milling due to chatter vibration is not only one of the main limitations for productivity and workpiece quality, especially for a finishing high-speed milling, but also shorten the life of the machines and tools evidently. In particular, the aerospace, etc. industries have a strong demand for increasingMRR. Therefore, machine-tool system has to operate close to the limit of its dynamic stability.

In addition, the manufactured structural parts in the aerospace industry become larger and more complex. If chatter vibration occurs during milling, the scrap rate of produced workpiece rises. This leads to immense economiclosses. To run the milling process close to the limit between stable and unstable cut, the prediction of the stability limit is absolutely necessary which helps in producing high quality products and maximum material removal rate (MRR) in real machining.Altintas et al. [1] established a method of predicting the lobe analytically. Vincent Thevenot et al. [2] introduced the dynamic behavioral variation of the part with respect to the tool position in order to predict the optimal cutting conditions during the machining process and this has led to the development of three dimensional stability lobe. In I. Mane et al [3], an integrated spindle - workpiece model is developed by coupling a rotor- dynamics based spindle FEM model and a thin walled Workpiece FEM model and it overcomes the limitation of Vincent Thevenet et al. by accounting the dynamic behavior of spindle.Aijun Tang et al. [4] presented a three dimensional stability lobe diagram by considering radial depth of $\operatorname{cut}(\mathrm{Z}$ axis) in end milling of thin walled plate.Guillem Quintana et al. [5] presented a new experimental method for identification of stability lobe diagram (SLD) in milling operations using an inclined workpiece.
O.B.Adetoro et al. [6] established a stability lobe diagram for thin walled Aluminium structures of different thickness.Both Finite Element analysis (FEA) and Fourier transform approach were used to obtain frequency response function (FRF) which is the prerequisite to create SLD. This paper presents a numerical approach in the prediction of chatter for three different rib thicknesses with the help of stability lobe diagram by extracting the workpiece FRF obtained from harmonic analysis. The stability lobe diagram is plotted for downmilling of a thin walled structure with radial depth of cut as $0.5 \mathrm{~mm}$ and cutter diameter as $4 \mathrm{~mm}$.

\section{Stability Lobe Theory}

Stability lobe diagram helps in predicting cutting parameters namely spindle speed and axial depth of cut that helps in chatter free machining.

The governing equations for predicting stability lobe are discussed below

The real $\left(G_{R}\right)$ and imaginary $\left(G_{I}\right)$ components of the transfer function for a certain chatter frequency can be calculated using the formulae.

$$
\begin{gathered}
\mathrm{G}_{\mathrm{R}}=\frac{\left(1-r^{2}\right)}{k\left[\left(1-r^{2}\right)^{2}+(2 \zeta r)^{2}\right]} \\
\mathrm{G}_{\mathrm{I}}=\frac{-2 \zeta r}{k\left[\left(1-r^{2}\right)^{2}+(2 \zeta r)^{2}\right]}
\end{gathered}
$$

where $\mathrm{r}=\mathrm{f} / \mathrm{f}_{\mathrm{n}}$

$\mathrm{f}_{\mathrm{n}}$ - Natural frequency $(\mathrm{Hz})$

f- Chatter frequency $(\mathrm{Hz})$

$\zeta$ - damping ratio

k- Stiffness(N/m)

It is also necessary to consider the average number of teeth during the cut $(\mathrm{m})$

$$
\mathrm{m}=\frac{N * P_{R}}{2 * D}
$$

where $\mathrm{D}$ is the tool diameter $(\mathrm{mm}), \mathrm{N}$ the number of teeth of the tool and $P_{R}$ the radial depth of cut.

The axial depth of cut is given by 


\section{International Journal of Science and Research (IJSR) \\ ISSN (Online): 2319-7064}

Index Copernicus Value (2013): 6.14 | Impact Factor (2015): 6.391

$$
b=-\frac{1}{2 * m * G_{R} * \text { 回 } * K s}
$$

where $K s$-specific cutting resistance $\left(\mathrm{N} / \mathrm{m}^{2}\right)$

$\mu$ - directional orientation factor

Minimum axial depth of cut occurs when $G_{R}$ is negative maximum and it occurs when

$\mathrm{r}=\sqrt{1+2 \zeta}$

$$
\mathrm{b}_{\min }=\frac{2 * k * \zeta *(1+\zeta)}{k s * \text { 回*m }}
$$

Roughness or waviness always exists on the machined surface of work piece due to vibrations. According to regenerative chatter theory, chatter occurs whenever there is a shift of the phase angle $\varepsilon$ between the current and previous surface waviness. Therefore, the ratio of chatter frequency $f$ to tooth-stroke frequency $\mathrm{f}_{\mathrm{t}}$ represents the number of surface waves between consecutive cutter teeth, and can be written as an integer $\mathrm{n}$ (also called the lobe number. $\mathrm{n}=0,1,2, \ldots$ ) plus a fraction of $\varepsilon / 2 \pi$ radians.

$$
\frac{f}{f_{t}}=\frac{r}{r_{t}}=n+\varepsilon / 2 \pi
$$

Where $r_{t}$ is the ratio between the tooth frequency and natural frequency $\left(r_{t}=f_{t} / f_{n}\right)$. The phase shift angle $\varepsilon$ between the current and previous surface waviness may be expressed as

$$
\begin{gathered}
\varepsilon=\pi+2 \tan ^{-1} \frac{G_{I}}{G_{R}} \\
\frac{f}{f_{t}}=\frac{r}{r_{t}}=n+\left(\frac{1}{2}\right)+\left(\frac{1}{\pi}\right) \tan ^{-1} \frac{-2 \zeta r}{\left(1-r^{2}\right)}
\end{gathered}
$$

Eq. 8 represents the relationships among the chatter frequency $\mathrm{f}$ (or $r$ ), the tooth frequency $\mathrm{f}_{\mathrm{t}}\left(\right.$ or $\left._{\mathrm{t}}\right)$, and the lobe number $\mathrm{n}$.

The spindle speed $N$ can be related to the tooth frequency $f_{t}$

$$
\mathrm{N}=\frac{\mathrm{ft} * 60}{n t}
$$

where $n_{t}$ is the number of teeth on the cutter.

\section{Determination of Damping Ratio}

The stability lobes calculation requires the dynamic parameters namely natural frequency, damping ratio and stiffness. The stiffness is determined through FRF and the damping ratio for an aluminum alloy is determined experimentally through impact hammer test as shown in Fig. 1(a).

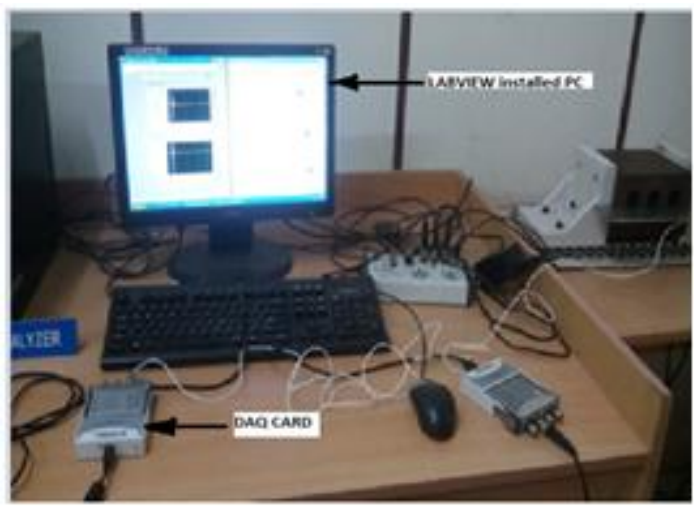

Figure 1(a): Experimental set up

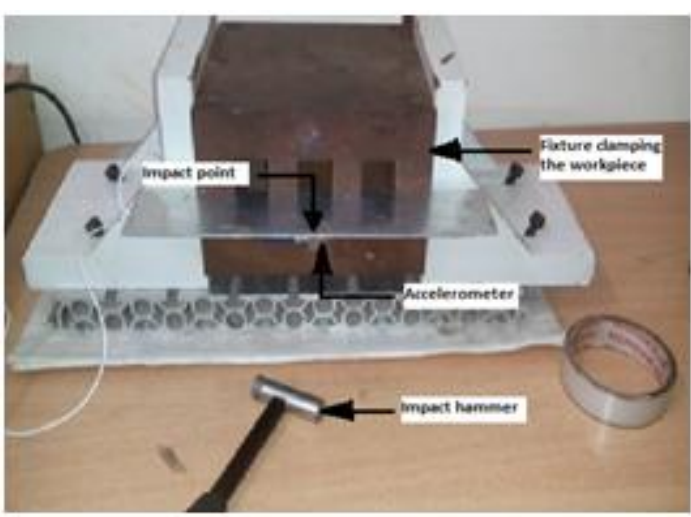

Figure 1(b): Accelerometer set up

The workpiece is held in the fixture as shown in Fig. 1(b) and it is excited using impact hammer. The accelerometer placed at the opposite side of the impact point measures the displacement signal in time domain as shown in Fig. 2.

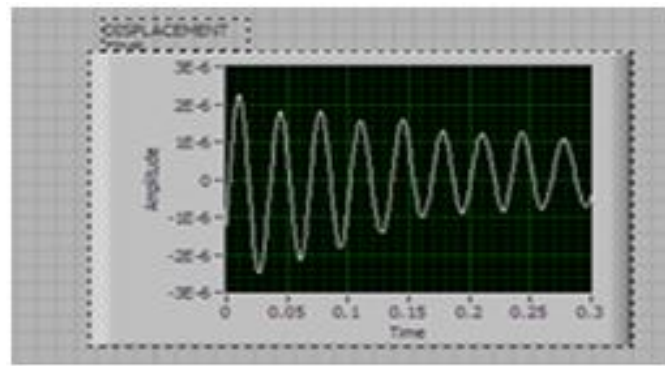

Figure 2: Exponential decay of displacement with respect to time

Using logarithmic decrement method the damping ratio of an aluminum alloy is found to be 0.02

\section{Finite Element Modelling}

The workpiece material used in the FEM model is Aluminum Alloy 6061. The material properties required for dynamic analysis are Density - $2700 \mathrm{~kg} / \mathrm{m}^{3}$, Young's Modulus $-70 \mathrm{GPa}$ and Poisson's ratio-0.33. Three different rib thickness are used in the finite element analysis (FEA). The dimensions [6] are shown in Fig. 3.

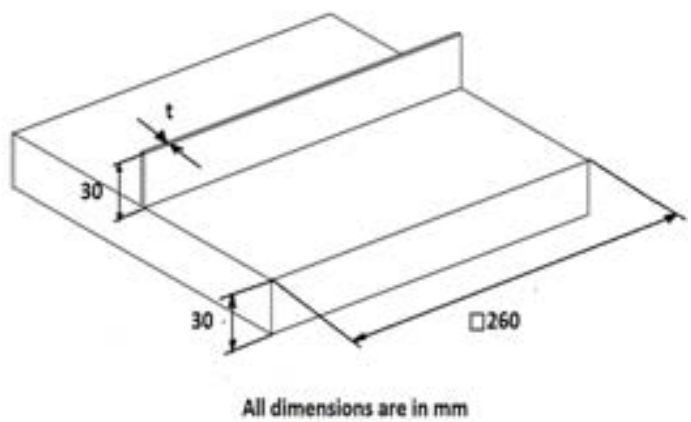

Figure 3: Dimensions of workpiece

Thechosen three rib thicknesses are $\mathrm{t}=1.5 \mathrm{~mm}, 3 \mathrm{~mm}$ $4.5 \mathrm{~mm}$. The assumption made here is that workpiece is flexible compared to the tool, which is much more rigid than 


\section{International Journal of Science and Research (IJSR) \\ ISSN (Online): 2319-7064}

Index Copernicus Value (2013): 6.14 | Impact Factor (2015): 6.391

the workpiece. Finite element model of workpiece is shown in Fig. 4.

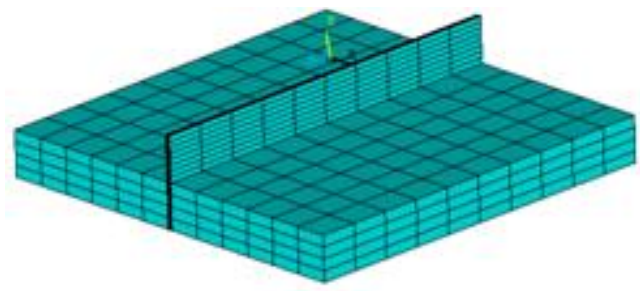

Figure 4: Finite element model of workpiece

\subsection{Modal analysis}

The model is fixed at the base and dynamic analysis is performed. The modal analysis of three rib thicknesses is shown in Table 1.

Table 1: Modal analysis results

\begin{tabular}{|c|c|c|c|}
\hline \multirow{2}{*}{$\begin{array}{c}\text { Mode } \\
\text { number }\end{array}$} & \multicolumn{3}{|c|}{ Natural frequency(Hz) } \\
\cline { 2 - 4 } & $1.5 \mathrm{~mm}$ & $3 \mathrm{~mm}$ & $4.5 \mathrm{~mm}$ \\
\hline 1 & 1403 & 2743 & 4032 \\
\hline 2 & 1445 & 2821 & 4143 \\
\hline 3 & 1575 & 3073 & 4505 \\
\hline 4 & 1796 & 3496 & 5114 \\
\hline 5 & 2111 & 4094 & 5978 \\
\hline
\end{tabular}

\subsection{Validation of finite element model}

The fundamental frequency of the above model is validated analytically using Euler- Bernoulli beam theory. The fundamental frequency of the beam (in $\mathrm{rad} / \mathrm{s}$ ) is given as

$$
\omega_{\mathrm{n}}=\frac{1.8751^{2}}{L^{2}} \sqrt{\frac{E * I}{\rho * A}}
$$

Converting to $\mathrm{Hz}$, the fundamental frequency is given by

$$
\mathrm{f}_{\mathrm{n}}=\frac{1.8751^{2}}{2 \pi L^{2}} \sqrt{\frac{E * I}{\rho * A}}
$$

Comparison of fundamentalnatural frequencies obtained from FEM method and analytical method is given in Table 2.

Table 2: Comparison of fundamental frequency

\begin{tabular}{|c|c|c|c|}
\hline \multirow{2}{*}{ Thickness(mm) } & \multicolumn{2}{|c|}{ Fundamental frequency (Hz) } & \multirow{2}{*}{$\%$ error } \\
\cline { 2 - 3 } & By FEM & By Analytical & \\
\hline 1.5 & 1403 & 1370 & 2.39 \\
\hline 3 & 2743 & 2741 & 0.06 \\
\hline 4.5 & 4032 & 4112 & 1.93 \\
\hline
\end{tabular}

Table 2 shows that the FEM results are closer to the analytical results and thus the above FEM model is validated analytically.

\section{Frequency Response Function}

Harmonic analysis is performed at the mid position of the rib and the predicted amplitude signals for each workpiece in frequency domain is shown in Fig. 5, Fig. 6 and Fig. 7

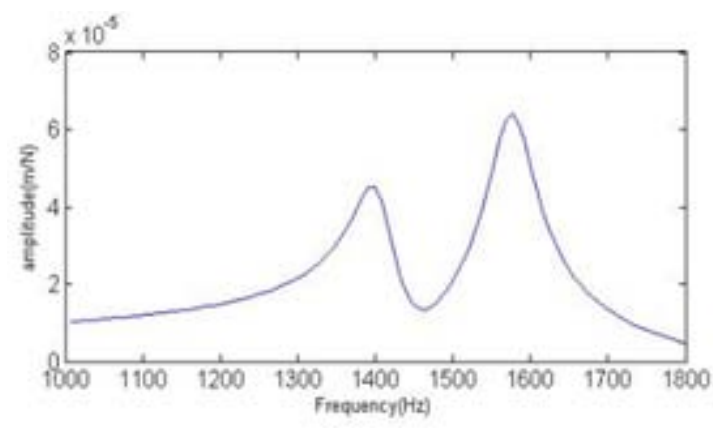

Figure 5: Predicted amplitude for workpiece $(\mathrm{t}=1.5 \mathrm{~mm})$

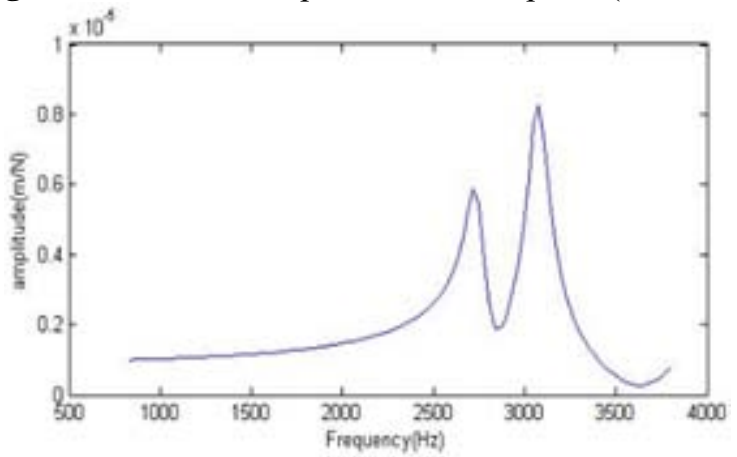

Figure 6: Predicted amplitude for workpiece $(\mathrm{t}=3 \mathrm{~mm})$

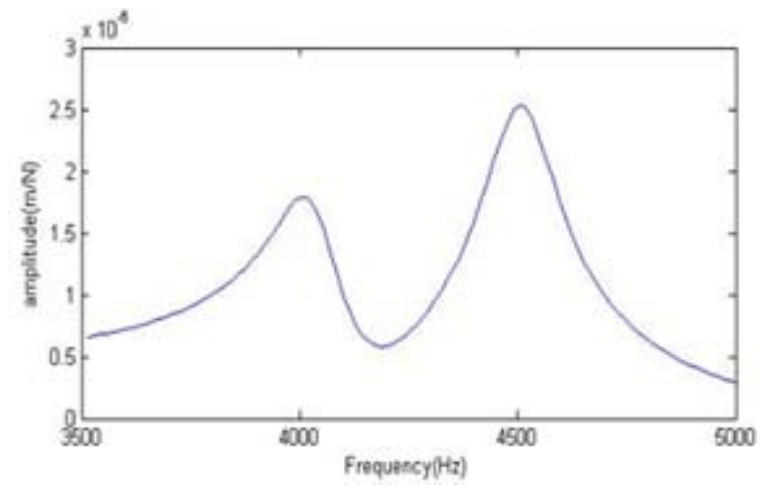

Figure 7: Predicted amplitude for workpiece $(\mathrm{t}=4.5 \mathrm{~mm})$

The real and imaginary components of FRF for $1.5 \mathrm{~mm}$ rib are shown in Fig.8(a) and Fig.8(b) respectively.

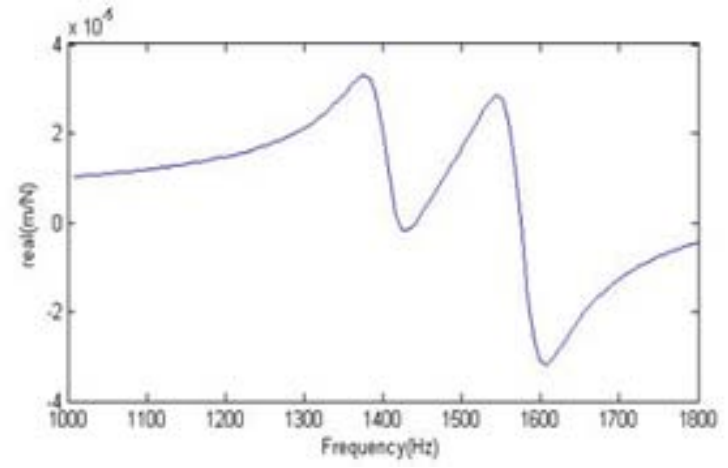

Figure 8(a): Predicted real part of FRF $(\mathrm{t}=1.5 \mathrm{~mm})$ 


\section{International Journal of Science and Research (IJSR) \\ ISSN (Online): 2319-7064}

Index Copernicus Value (2013): 6.14 | Impact Factor (2015): 6.391

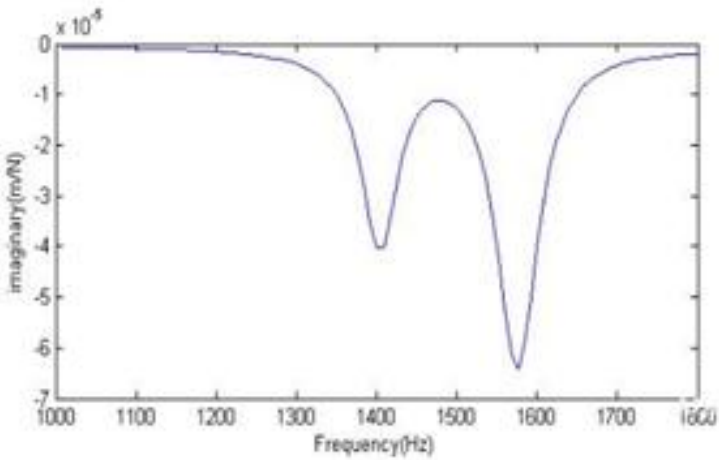

Figure 8(b): Predicted imaginary part of FRF $(\mathrm{t}=1.5 \mathrm{~mm})$

Similarly the real and imaginary part of FRF for 3 and 4.5 $\mathrm{mm}$ rib thickness has been extracted by finite element modeling approach.

The dynamic stiffness $(\mathrm{k})$, natural frequency and deflection per unit force for three workpiece obtained from FRF are given in Table 3 .

Table 3: Comparison of dynamic stiffness

\begin{tabular}{|c|c|c|c|}
\hline $\begin{array}{c}\text { Rib thickness } \\
(\mathrm{mm})\end{array}$ & $\begin{array}{c}\text { Natural frequency } \\
(\mathrm{Hz})\end{array}$ & $\begin{array}{c}\mathrm{K} \\
(\mathrm{N} / \mathrm{mm})\end{array}$ & $\begin{array}{c}\text { Deflection } \\
(\mathrm{N} / \mathrm{m})\end{array}$ \\
\hline 1.5 & 1575 & 384 & $6.4 \times 10^{-5}$ \\
\hline 3 & 3073 & 3121 & $8.2 \times 10^{-6}$ \\
\hline 4.5 & 4505 & 10787 & $2.5 \times 10^{-6}$ \\
\hline
\end{tabular}

From Table 3 it is inferred that as rib thickness doubles stiffness of the rib increases cubic times.

The natural frequency increases for higher rib thickness because of the increase in stiffness of the structure.

\section{Stability Lobe Diagram}

The stability lobe diagram requires three main input parameters namely damping ratio, stiffness and natural frequency. Stability lobe diagram is generated using MATLAB software.Influence of rib thickness on stability is shown in Fig. 9

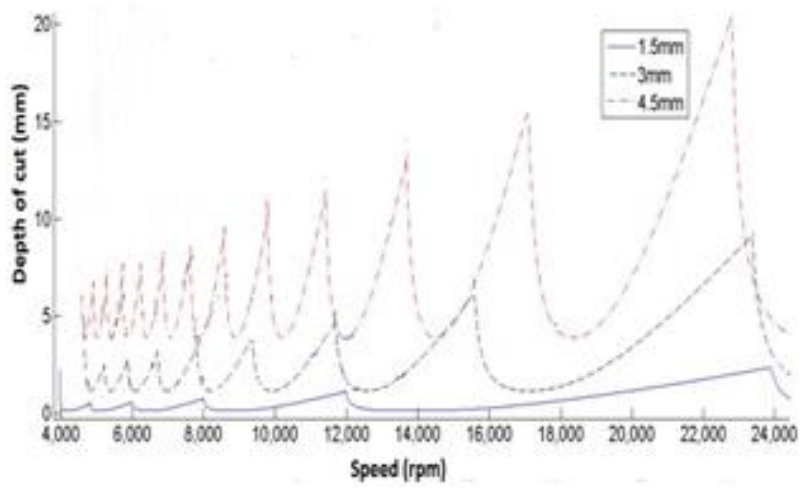

Figure 9: Influence of rib thickness on stability

\subsection{Minimum depth of cut $\left(b_{\min }\right)$}

The portion of the stability lobe below the minimum depth of cut value is termed as unconditional stable zone where chatter never occurs at all spindle speeds. The minimum depth of cut for each rib thickness is obtained from the lobe and is shown in Table4.
Table 4: Minimum depth of cutb $b_{\min }$

\begin{tabular}{|c|c|}
\hline Rib thickness $(\mathrm{mm})$ & Predicted $\mathrm{b}_{\min }(\mathrm{mm})$ \\
\hline 1.5 & 0.14 \\
\hline 3 & 1.17 \\
\hline 4.5 & 3.89 \\
\hline
\end{tabular}

On comparing table 3 and 4 it is clear that stiffness of the structure directlyinfluences minimum depth of cut value as seen in eq. (5)and it is minimum for $1.5 \mathrm{~mm}$ rib because of thereduction in stiffness. When the workpiece is milled from $4.5 \mathrm{~mm}$ to $1.5 \mathrm{~mm}$ the minimum axial depth of cut should be in the range of $3.89 \mathrm{~mm}$ to $0.14 \mathrm{~mm}$. Trend line has been drawn with the second order polynomial equation as shown in Fig. 10 that helps in selecting the minimum depth of cut at intermediate stages of machining.

Theequation for trend line is given as $\mathrm{Y}=0.3756 \mathrm{X}^{2}-1.0033 \mathrm{X}+0.8$

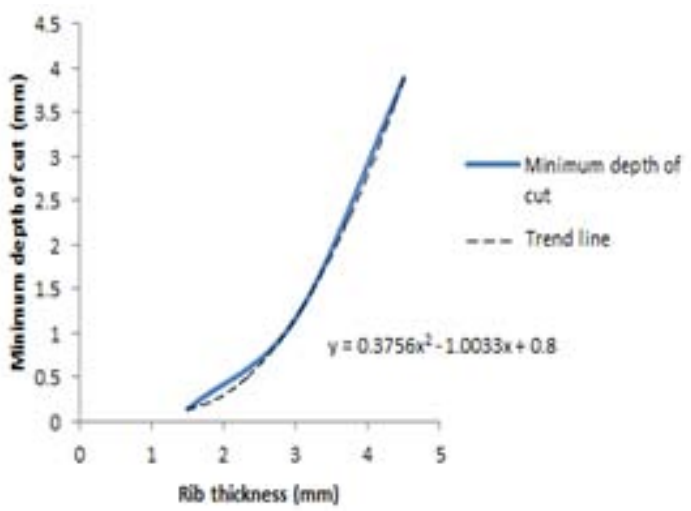

Figure 10: Predicted minimum depth of cut for various rib thickness

\section{Conclusion}

The presence of chatter while machining affects the workpiece in terms of surface quality. This paper has discussed the prediction of chatter for three different rib thicknesses with the help of stability lobe diagram by extracting the workpiece FRF obtained from harmonic analysis and the minimum depth of cut has been determined while downmilling the Aluminiumplate from $4.5 \mathrm{~mm}$ thick to $1.5 \mathrm{~mm}$ thick. Trend line also has been developedinorder to predict the minimum depth of cut at intermediate stages of machining.

\section{References}

[1] Y. Altintas, E. Budak, Analytical prediction of stability lobes in milling, CIRP Annals (1) (1995) 357-362

[2] Vincent Thevenenot, Lionel Arnaud, GllesDessein, Gilles Cazenave-Larroche, Integration of dynamic behavior variations in the stability lobes method: $\mathrm{Ad}$ lobes construction and application to -thin walled structure milling, International journal of Advanced Manufacturing Technology (2006) 27:63-644

[3] I. Mane, V. Gagnol, B.C. Bouzgarrrou, P, ray, Stabilitybased spindle speed control during flexible workpiece high-speed milling, International Journal of Machine Tools \& Manufacture 48 (2008) 184-194 


\section{International Journal of Science and Research (IJSR) \\ ISSN (Online): 2319-7064}

Index Copernicus Value (2013): 6.14 | Impact Factor (2015): 6.391

[4] Aijun Tang, Zhanqiang Liu, Three-dimensional stability lobe and maximum material removal rate in end milling of thin-walled plate, International Journal of Machine Tools \& Manufacture (2009) 43: 33-39

[5] Guillem Quintana, JoaquimCiurana, Daniel Teixidor, A new experimental methodology for identification of stability lobes diagram in milling operations, , International Journal of Machine Tools \& Manufacture 48 (2008): 1637-1645

[6] O. B. Adetoro, P. H. Wen, W. M. Sim, R. Vepa, Stability Lobes Prediction in Thin Wall Machining, Proceedings of the World Congress on Engineering 2009 Vol I

Volume 5 Issue 7, July 2016 www.ijsr.net 